\title{
ABORDANDO A SEXUALIDADE NA ESCOLA: ESPAÇO DE REFLEXÃO E INTERVENÇÃO ${ }^{1}$
}

\author{
Raquel Evelly Vieira de Araújo, Universidade Federal de Campina Grande (UFCG) \\ raquelevelly75@gmail.com \\ Geovanni Mendes Amancio, Universidade Federal de Campina Grande (UFCG), \\ geovanniamancio@gmail.com \\ Maria Thaís de Oliveira Batista, Universidade Federal de Campina Grande (UFCG), \\ taholiveira.thais@gmail.com
}

\begin{abstract}
RESUMO
O referido trabalho objetiva abordar uma discussão sobre sexualidade, a fim de propiciar reflexões acerca de tal objeto, almejando caminhos a serem traçados entre educadores e família, ressaltando a relevância da parceria destes. Para tanto, o estudo foi realizado na perspectiva de aprofundar conhecimentos sobre o conceito de sexualidade, sua importância, o papel do educador ao auxiliar o sujeito em sua formação, explanando o déficit encontrado nos profissionais em relação à temática, considerando também, como fonte de discussão, as contribuições insubstituíveis da família. O estudo sustenta-se a partir de uma pesquisa bibliográfica, abordando textos de autores específicos e conceituados na área. Concluímos que a escola por si só não dará conta da demanda que um trabalho com a sexualidade permite ao individuo, visto que ainda hoje, educadores e pais possuem receio de conversar sobre assuntos do tipo com seus alunos/filhos. Porém, acreditamos que, se trabalhada conjuntamente, a probabilidade de êxito para que o sujeito construa e aprimore seu entendimento sobre a sexualidade é satisfatória. O diálogo abre espaço entre ambos, evitando a deseducação do indivíduo, suprindo assim, suas necessidades de conhecer, contribuindo para sua construção de identidade sexual, sem deixar de lado seus valores que fora cultivados no âmbito familiar.
\end{abstract}

PALAVRAS-CHAVE: sexualidade 1; escola 2; família 3; educação 4.

\section{ADDRESSING SEXUALITY AT SCHOOL: SPACE OF REFLECTION AND INTERVENTION}

\begin{abstract}
The refered work aims to address a discussion about sexuality in order to provide reflections on such an object, aiming for paths to be drawn between educators and family, emphasizing partnership's relevance. Thereunto, the study was conducted in a deepening perspective about knowledge and sexuality's concept, its importance, educator's role to assist subject in his formation, explaining deficit found in professionals and relation to this thematic, considering also, as a source of discussion, the family's irreplaceable contributions. The study is sustained from a bibliographical research, addressing specific texts of reputable authors. We conclude that the school alone will not realize the

${ }^{1} \mathrm{O}$ presente trabalho (não) contou com apoio financeiro de nenhuma natureza para sua realização.
\end{abstract}


demand that a job with sexuality allows the individual, since even today, educators and parents are afraid to talk about type issues with their pupils/children. However, we believe that, if worked together, the probability of success for subject to construct and improve his understanding about sexuality is satisfactory. The dialogue opens space between both, avoiding diseducation of individual, thereby supplying their needs to know, contributing to their construction sexual identity, without leaving aside their values that were cultivated within ambit family.

KEYWORDS: sexuality; school 2; family 3. Education 4.

\section{ABORDANDO LA SEXUALIDAD EN LA ESCUELA: ESPACIO DE REFLEXIÓN E INTERVENCIÓN}

\section{RESUMEN}

El trabajo tiene como objetivo generar una discusión sobre la sexualidad, con la finalidad de proporcionar reflexiones acerca de tal objeto, definiendo caminos a seguir por educadores y familia, resaltando la relevancia de la asociación de éstos. El estudio se ha realizado desde la perspectiva de profundizar en los conocimientos sobre el concepto de la sexualidad, su importancia, el papel del educador al ayudar al sujeto en su formación, explicando el déficit encontrado en los profesionales en relación a dicha temática, considerando también como fuente de discusión, las contribuciones insustituibles de la familia. El estudio se sustenta en una investigación bibliográfica, abordando textos de autores específicos y especializados en el área. Concluimos que la escuela por sí sola no dará cuenta de la demanda que un trabajo con la sexualidad permite al individuo, visto que aún hoy, educadores y padres tienen recelo a conversar sobre asuntos de este tipo con sus alumnos/hijos. Sin embargo, acreditamos que, trabajando conjuntamente, la probabilidad de éxito para que el sujeto construya y mejore su entendimiento sobre la sexualidad es satisfactoria. El dialogo fomenta el entendimiento entre ambos, evitando lagunas en la educación del individuo, complementando así sus necesidades de conocer y contribuyendo en la construcción de su identidad sexual, sin dejar de lado los valores que fueron inculcados en el ámbito familiar.

PALABRAS CLAVES: sexualidad 1; escuela 2; familia 3; educación 4.

\section{INTRODUÇÃO}

O presente trabalho objetiva discutir a relevância em abordar a temática da sexualidade no âmbito escolar e familiar, a fim de esclarecer possíveis dúvidas e explorar os conhecimentos prévios pela sociedade, tendo em vista o aprimoramento da discussão sobre a temática, como forma de fechar lacunas inerentes nesse processo de formação pessoal do sujeito.

É relevante destacar que as variáveis sociais que se introduzem nesse assunto considerado polêmico e omisso pelos pais e pela comunidade escolar, surgem de forma a influenciar direta ou indiretamente na compreensão construtiva da formação do sujeito. Nesse 
sentido, vê-se a importância de se planejar pedagogicamente a respeito dessa temática tão delicada de discutir em sala de aula, uma vez em que o professor não se sente a vontade em expor o conteúdo ou tampouco busca meios para o desenvolvimento através de debates, concepções acerca do tema, dúvidas etc.

Assim, na contemporaneidade, é natural que se veja e presencie episódios diários de crianças e adolescentes falando sobre sexualidade em qualquer e todo tipo de ambiente, o que se considera arriscado, haja vista a ingenuidade sobre tal. Contudo, sabemos que essas abordagens não são/foram tão presentes na formação pessoal e acadêmica de muitos sujeitos.

Para embasamento teórico para esse trabalho, foram utilizados como referências para auxiliar na pesquisa textos de autores nacionais e internacionais como LOURO (2008), SOUZA (2002), WEREBE (1998), GONÇALVES (2001), LAKATOS E MARCONI (1987) e CORTEZ (2008).

Consideramos o tema de suma importância, atendendo a necessidade da temática para discussão em sala de aula, levando em conjunto o âmbito familiar para satisfazer a curiosidade existente nos alunos acerca da sexualidade e sua relevância, propiciando os mesmos a se conhecerem, tanto no desenvolvimento biológico quanto psicossocial.

\section{METODOLOGIA}

O referido trabalho é de cunho bibliográfico, tendo como aporte teórico textos relacionados à sexualidade e o papel da família nesse processo educativo, com objetivo de refletir e esclarecer dúvidas existentes sobre a temática. De acordo com Gonçalves (2001) a pesquisa bibliográfica é caracterizada pelo seu desenvolvimento mediante a explanação de ideias, com objetivo de obter informações gerais, sendo uma primeira prática de proximidade entre discentes e determinado(os) autor(es) em um determinado assunto a ser estudado.

Para os estudiosos Lakatos e Marconi (1987) esse estudo possibilita ao pesquisador acesso de informações em torno do material que esta sendo estudado; possibilitando diversas fontes de estudos, embasadas teoricamente em autores nacionais/internacionais, compreendendo, amplamente, ângulos de modo que contribua para a formação do pesquisador, para seu posicionamento individual e dos leitores, buscando soluções sob a temática. 
A formação profissional de cada sujeito está relacionada à importância dada ao estudo, pois, no ato de pesquisar, o discente inicia sua leitura propiciando o surgimento de interpretações, formando seu conhecimento científico e aprimorando-o com o decorrer dos estudos.

\section{ASPECTOS HISTÓRICOS E CONCEITUAIS ACERCA DA SEXUALIDADE}

Discutir sexualidade mesmo nos dias de hoje ainda pode ser considerado, muitas vezes, assunto polêmico e causador de repreensões no âmbito escolar. Há muitos anos fomos educados de maneira que assuntos como esses só poderiam se fazer presentes quando chegássemos a maior idade, por mais que saibamos que a sexualidade se constrói ao longo do desenvolvimento biológico e social. Para que o entendimento sobre nosso trabalho seja inteiramente eficaz, é importante uma explanação geral sobre o seu progresso ao longo dos anos.

No ano de 1930, muitos professores foram jubilados e presos, por incluírem nos planejamentos das aulas o ensino acerca da temática sexualidade na escola. De acordo com Werebe (1998) na ditadura militar, em 1965, uma portaria estabelecida pelo secretário de Estado dos Negócios da Educação do Estado de São Paulo, proibiu educadores do ensino secundário, especificamente das disciplinas de Biologia e de Sociologia, de exporem nas aulas, assuntos relacionados sobre a sexualidade e contracepção. Júlia Steimbruck, carioca e que fora deputada em 1968 e devido o interesse crescente sobre a educação sexual entre os professores e a sociedade como um todo, criou um projeto de Lei que tinha como objetivo tornar obrigatório o ensino sobre a educação sexual no âmbito escolar.

Com o surgimento de diversas doenças sexualmente transmissíveis, que desencadeou na proliferação do vírus HIV e com a preocupação da família devido à gravidez indesejada na adolescência, nas décadas de 70 e 80, as pessoas passaram a ter maiores curiosidades acerca da sexualidade e como consequência, na década de 90, foi comprovada em uma pesquisa do Instituto Data Folha, divulgada em 1993, que $86 \%$ da população que colaboraram para a pesquisa, eram favoráveis à inclusão das discussões sobre Orientação Sexual nos currículos escolares. O governo efetua, então, aos Parâmetros Curriculares Nacionais, a elaboração do 
tema "Pluralidade cultural e orientação sexual", tratando-se de questões acerca da sexualidade nas escolas.

Para construir identidade de gênero e sexualidade, o indivíduo passa por formações e transformações ao longo do seu desenvolvimento biológico e social. A adolescência concebe uma fase de transição da infância para a fase adulta, conduzindo cargas significativas de dúvidas, medos, aspectos morais, amadurecimento corporal, alterações emocionais que desencadeará na formação da identidade do indivíduo. Ao abordar essa temática, compreendemos que a sexualidade "é um termo amplamente abrangente que dificilmente se encaixa em uma definição única e absoluta.” (BRASIL, 2001, p. 117).

Nessa perspectiva, Louro (2008) conceitua que, para construção da identidade de gênero e sexualidade o indivíduo passará por diversas aprendizagens durante sua formação, o qual envolve vivências tanto no âmbito social, quanto no âmbito cultural em que este se socializa. Segundo Souza (2002) a educação sexual se dá de forma informal e contínua, pois, todos se educam e reeducam frequentemente, tendo em vista que os pioneiros dessa devida educação primária sobre a sexualidade é a família, mesmo que nos dias de hoje, o conjunto familiar esteja mais ausente do que antigamente e os sujeitos se encontrem e convivam mais no âmbito escolar. Louro (1997) difere o sexo em si da sexualidade, anunciando que a sexualidade envolve o modo de como as pessoas lidam com seus prazeres e desejos, com aspectos culturalmente maiores do que o biológico.

É notário, que "as manifestações da sexualidade afloram em todas as faixas etárias." (BRASIL, 2001, p. 291). Partindo dessa definiç̧ão, compreendemos que a sexualidade é um dos aspectos indispensável da vida humana, que se inicia logo após o nascimento até a vida adulta do sujeito. Por isso, faz-se cada vez mais necessárias discussões acerca da temática nos mais diversos espaços, e dentre tais as escolas e a família, no qual o individuo irá construir sua identidade perante a sociedade.

\section{EDUCAÇÃO SEXUAL: PAPEL DA ESCOLA EM CONJUNTO COM A FAMÍLIA}

A escola tem um papel fundamental diante da colaboração com a formação do indivíduo. Segundo Souza (1991), a educação sexual é constituída por diversas condições para que o indivíduo possa assumir seu corpo e sua sexualidade, livres de medos, 
preconceitos que existem em nossa sociedade, designando objetivos que a educação sexual sobpõe ao sujeito. Sabemos que a escola juntamente com a família são corresponsáveis pela formação de identidade e da sexualidade do indivíduo. O diálogo que pode/deve ser abordado sobre esse tema trás conhecimentos e "liberdade", auxiliando na eliminação de tabus e preconceitos. De acordo com Louro (1997) os discursos pedagógicos buscam explicar que as relações que constituem as práticas escolares devem conter proximidade com as relações familiares.

Muitos profissionais da educação reprimem e ignoram essas dúvidas presentes em seus alunos, impedindo que estes não explanem suas curiosidades. Com isso, a escola deposita no âmbito familiar, toda carga de responsabilidade acerca da construção da sexualidade do indivíduo/aluno, podendo resultar em conflitos familiares e facilitando assim a deseducação sexual, induzindo o sujeito a riscos relacionados às práticas sexuais. Tendo em vista que a Orientação Sexual citada pelos Parâmetros Curriculares Nacionais " [...] não concorre com a educação da família e muito menos substitui, mas a complementa [...]" (BRASIL, 1998, p. 299).

Como é perceptível na afirmação acima, vimos que o trabalho para discutir tal assunto necessita ser efetuado em conjunto com a família e escola, pois o indivíduo antes de iniciar seu processo de formação no âmbito escolar, já possuem cargas de valores éticos, morais e ideologias, que foram adquiridas em seu convívio familiar.

Souza (1991, p. 41) com relação à postura dos professores afirma que "o educador mostra sua educação ao transmitir conhecimento sobre educação. Será preciso que esta pessoa, disposta a educar, se eduque antes, se analise, se informe. Pense no que está fazendo.”, ou seja, para que o educador em sala de aula efetive seu trabalho em orientar seus alunos, abordando essa temática, é necessário que, se haja dificuldade em discutir esse tema, este educador venha a superar suas dificuldades individuais, para que consiga orientar de maneira adequada o alunado, respeitando suas crenças e valores. A família em seu contexto geral é a primeira instância educativa dos sujeitos, assim como a sociedade num todo, e por isso é de suma importância sua participação nos projetos exercidos pela escola.

Segundo Cortez $(2008$, p. 1) afirma que, “[...] hoje a escola é que possui cada vez mais esta responsabilidade de educar os alunos para uma sexualidade saudável." Mas é notória a 
carência de profissionais despreparados para lidar com o assunto, induzindo assim, a má formação do individuo como cidadão quanto sua sexualidade.

Por isso, as discussões acerca da Orientação Sexual que a escola pode trabalhar, não estão concorrendo com a educação gerada pela família. A escola ao elaborar seus projetos e formas de educar sexualmente seu alunado, deve conhecer as necessidades de cada um, para que possa aprimorar suas metodologias de ensino, que resultarão de maneira qualificada no êxito em seu trabalho.

O sentir-se bem no âmbito da sexualidade constrói de maneira satisfatória a saúde e a satisfação interpessoal. Deste modo, a necessidade de envolver a escola para o processo de ensino sobre a educação sexual, faz-se indispensável para esclarecer e refletir com o alunado, por exemplo, as mais diversas opções sexuais existentes na sociedade, a fim de obter o reconhecimento dos alunos para que possam desfrutar de maneira responsável e saudável à sexualidade, podendo ter uma visão mais positiva sob o tema.

Portanto, para que a sociedade seja educada sexualmente, os indivíduos devem esta ciente da sua sexualidade ou de assuntos relacionados, reconhecendo que precisamos constantemente de um maior diálogo entre as famílias e escolas acerca da temática, para que os filhos/alunos tornem-se maduros diante suas escolhas, respeitando sempre as diferenças do outro.

\section{CONSIDERAÇÕES FINAIS}

Se levarmos em consideração os avanços atuais da nossa realidade em pleno século XXI, é perceptível que ainda deixa muito a desejar. Seriam necessários inúmeros estudos/pesquisas para sabermos as necessidades de discussões em torno da sexualidade, com ênfase na parceria escola-família-aluno, pois mesmo com toda modernidade e de fácil acesso via: internet, TV, entre outras tecnologias que estão disponíveis para o individuo, é considerado essa temática como tabu.

É de convívio nos depararmos com informações pelo jornal, TV, internet, casos que envolvam a sexualidade. A gravidez indesejada, DSTs (Doenças sexualmente transmissíveis), despertam na sociedade curiosidades acerca dessa temática, porém muitas vezes no âmbito escolar e familiar, as informações sobre é vaga e acaba não suprindo a necessidade do 
aluno/filho que, consequentemente, irá procurar respostas às suas indagações fora de casa/escola. Nesse contexto, é de suma importância uma discursão significativa por todos os indivíduos envolvidos nesse processo de ensino-aprendizagem, para que as demandas sejam alcançadas.

Podemos destacar como ponto de grande relevância nesse contexto sobre sexualidade, a necessidade de incluir a família no processo de Orientação Sexual em conjunto com a escola. Aprimorando o diálogo, desencadeando espaço entre ambos, para que evite a deseducação do indivíduo, pois, a escola como também a família por si só, não dará conta de auxiliar os sujeitos tanto para uma educação em seu contexto geral quanto para o sexual, mas sim em parceria, para que assim, informe-os acerca do tema, contribuindo para sua formação quanto pessoa.

Em meio a esse debate, o professor possui um papel insubstituível para a formação educativa e social do educando, principalmente no ensino sobre a sexualidade. O papel do docente seria auxiliar seus alunos, promovendo discursão, apresentando caminhos para que os mesmos encontrem "soluções", de maneira dinâmica e construtiva, mas nunca esquecendo que cada individuo possui suas especificidades.

Todavia ao ressaltar a sexualidade como um processo de construção cultural e histórica, é perceptivel que as escolas ainda possuem carência em profissionais capacitados para lidar com tal realidade, pois, mesmo com todo avanço, há desafios a serem resolvidos para que a educação sexual seja vista como importante e indispensável, pois esta é inerente na vida de todos os sujeitos.

\section{REFERÊNCIAS BIBLIOGRÁFICAS}

BRASIL. Ministério de Educação. Parâmetros Curriculares Nacionais. 1998.

BRASIL. Parâmetros Curriculares Nacionais. Pluralidade cultural e orientação sexual. 3 ed. A secretaria, Brasília, 2001.

CORTEZ, Samuel. A sexualidade na escola. Disponível em: http://profecortez.blogspot.com.br/2008/01/sexualidade-na-escola.html. Acesso em 01 de julho de 2017. 
GONÇALVES, Elisa Pereira. Conversa sobre iniciação a pesquisa científica. ed. Alínea: Campinas, 2001.

LAKATOS, Eva Maria; MARCONI, Marina de Andrade. Pesquisa Bibliográfica. In:

Metodologia do trabalho científico. 2.ed. São Paulo: Atlas, 1987. cap. 2, p. 44-79.

LOURO, Guacira Lopes. Gênero e sexualidade: pedagogias contemporâneas. ProPosições, v. 19, n. 2 (56) - publicado em 2008. Disponível em: < http://www.scielo.br/pdf/pp/v19n2/a03v19n2.pdf>. Acesso em 14 de julho de 2017. LOURO, Guacira Lopes: Gênero, sexualidade e educação: Uma perspectiva pósestruturalista. Petrópolos, RJ. ed. Vozes, 1997.

SOUZA, Hália Pauliv de. Convivendo com seu sexo: pais e professores. São Paulo. ed. Paulinas, 1991.

SOUZA, Hália Pauliv de. Sexo, energia presente em casa e na escola. São Paulo. ed. Paulinas, 2002.

WEREBE, Maria José Garcia. Sexualidade, Política e Educação. Campinas: ed. Autores Associados, 1998. 